\title{
Soft Energy Paths Revisited: Politics and Practice in Energy Technology Transitions
}

\author{
Chelsea Schelly * and Aparajita Banerjee \\ Department of Social Sciences, Michigan Technological University, Houghton, MI 49931, USA; \\ abanerj1@mtu.edu \\ * Correspondence: cschelly@mtu.edu; Tel.: +1-906-487-1759 \\ Academic Editor: Palmiro Poltronieri \\ Received: 22 August 2016; Accepted: 12 October 2016; Published: 14 October 2016
}

\begin{abstract}
This paper argues that current efforts to study and advocate for a change in energy technologies to reduce their climate and other environmental impacts often ignore the political, social, and bodily implications of energy technology choices. Framing renewable energy technologies exclusively in terms of their environmental benefits dismisses important questions about how energy infrastructures can be designed to correspond to democratic forms of socio-politics, forms of social organization that involve independence in terms of meeting energy needs, resilience in terms of adapting to change, participatory decision making and control, equitable distribution of knowledge and efficacy, and just distribution of ownership. Recognizing technological choices as political choices brings explicit attention to the kinds of socio-political restructuring that could be precipitated through a renewable energy technology transition. This paper argues that research on energy transitions should consider the political implications of technological choices, not just the environmental consequences. Further, emerging scholarship on energy practices suggests that social habits of energy usage are themselves political, in that they correspond to and reinforce particular arrangements of power. Acknowledging the embedded politics of technology, as the decades' old concept of soft path technologies encourages, and integrating insights on the politics of technology with insights on technological practices, can improve future research on energy policy and public perceptions of energy systems. This paper extends insights regarding the socio-political implications of energy paths to consider how understandings of energy technologies as constellations of embedded bodily practices can help further develop our understanding of the consequences of energy technologies, consequences that move beyond environmental implications to the very habits and behaviors of patterned energy usage, which are themselves arguably political. This paper calls for future research that involves explicit examination of the relationship between technologies, socio-political distributions of power and access to energy resources, the social organization of energy practices, and options for energy transitions not just in terms of energy source, but also in terms of scale, design, and modes of ownership and control.
\end{abstract}

Keywords: soft energy paths; appropriate technology; energy transitions; renewable energy; energy politics; energy practices

\section{Introduction}

The groundbreaking work of Amory Lovins on soft energy paths [1-3] was part of a larger movement interested in connecting and critiquing both the environmental and socio-political consequences of energy technology choices. For scholars of the appropriate technology movement, these environmental and socio-political issues were not discussed in isolation but were part of an encompassing perspective on the relationships among society, nature, and technology. Yet most contemporary work on the environmental urgency of facilitated energy transitions that move 
away from fossil fuel dominated energy networks largely ignores insights and issues regarding the implications of technological choices for socio-political arrangements. This paper argues that current efforts to study and advocate for a change in energy technologies to reduce their climate and other environmental impacts often disregard the implications of energy technology choices in terms of two essential components: politics and practice. Recognizing how politics and practice are embedded in technologies may offer two distinct advantages. First, seeing technological choices as political choices, but not exclusively in terms of the politics of environmentalism, may facilitate the process of finding more common ground for promoting a renewable energy transition than polarizing environmental politics. The current frame of renewable energy technologies as environmentally responsible choices may limit support for their adoption [4,5], particularly in the context of the United States, where environmental issues are highly contentious. Second, recognizing technological choices as political choices that also shape habitual bodily practice may bring more explicit attention to the kinds of infrastructural and economic restructuring that could be precipitated through a renewable energy technology transition. This perspective encourages research that explicitly examines the kinds of social structures that humans desire (rather than interrogating environmental attitudes, values, or concerns, narrowly conceived) and the technologies that could bring about the desired socio-politics and practices. Connecting the classic argument regarding the political implications of energy technologies from Lovins and the appropriate technology movement with more recent scholarship on energy technologies and social practices helps to extend politics into the realm of bodily habits and patterns of technological engagement. Thus, acknowledging that energy technologies have consequences for both socio-politics and practice can shift the study and promotion of a renewable energy transition.

\section{The History of Thought on Soft Energy Paths}

In the 1960s and 1970s, as the United States began to emphasize technological development based on large scale, centralized, and fossil fuel based technological infrastructures as a means of economic growth in so-called "developing" nations, a movement of both scholars and practitioners emerged to suggest an alternative. Dubbed the appropriate technology movement, this way of thinking recognized that some technological systems-namely those that are megalithic, monolithic, and fossil fuel reliant, like the systems of intensive, fertilizer and tractor based agriculture being pushed in domestic and international contexts during the Green Revolution as well as the systems of centralized electricity generation and transmission-are, simply put, inappropriate, due to both their environmental and their socio-political consequences. Amory Lovins characterized these dominant energy systems as "hard"-inflexible and unresponsive to the needs of real human beings—and the alternative option as "soft." The choice to pursue hard energy paths versus soft energy paths, or centralized versus appropriate technologies, was explicitly articulated as a political choice. Langdon Winner, a scholar who also views technologies as inherently political, defines politics as "arrangements of power and authority in human associations as well as the activities that take place within those arrangements" [6] (p. 22). Technologies are inherently political in the sense that material systems support and even necessitate particular forms of political arrangement in terms of access to knowledge, resources, sustenance, and wellbeing; "technology is designed not only to perform a material function but also to express and coercively reinforce beliefs about the differential allocation of power, prestige, and wealth in society" [7] (p. 283). As Amory Lovins writes, "The distinction between hard and soft energy paths rests not on how much energy is used, but on the technical and socio-political structure of the energy system, thus focusing our attention on consequent and crucial political differences" [2] (p. 38).

Lovins argued that soft path energy technologies share five characteristics: (1) they rely on renewable energy flows ("on energy income, not on depletable energy capital"); (2) they are diverse and distributed, so that the total supply of energy is "an aggregate of very many individually modest contributions, each designed for maximum effectiveness in particular circumstances"; (3) they are contextually adaptable and "relatively low-technology—which does not mean unsophisticated, but 
rather, easy to understand and use without esoteric skills, accessible rather than arcane"; (4) they are designed so that their scale and geographic distribution corresponds to actual human need; (5) they are designed so that energy quality corresponds to end-use, rather than a one-size-fits-all approach to energy source generation [2] (pp. 38-39).

This list of characteristics considers both technological factors (like size, scale, and energy supply quality) as well as the environmental considerations that often shape conversations about the role of energy policy in contemporary climate change mitigation efforts (in other words, renewable energy sources). Importantly, this list also includes technological characteristics that indicate the socio-political nature of technological choices. Indeed, Lovins continues on to write, "Perhaps the most profound difference between the soft and hard paths is their domestic socio-political impact ... In an electrical world, your lifeline comes not from an understandable neighborhood technology run by people you know who are at your own social level, but rather from an alien, remote, and perhaps humiliatingly uncontrollable technology run by a faraway, bureaucratized, technical elite who have probably never heard of you. Decisions about who shall have how much energy at what price also become centralized-a politically dangerous trend because it divides those who use energy from those who supply and regulate it" [2] (p. 54).

This kind of bold statement connecting technological choices to their socio-political consequences was crucial to the articulation of the appropriate technology movement. Whether working on their own back-to-the-land cabins and distributed technological systems [8] or writing about "tools for conviviality" $[9,10]$, the appropriate technology movement encompassed a broad critique of the socio-politics of the dominant energy regimes. For Lovins and others writing during the appropriate technology movement of the 1960s and 1970s, choices about energy technology development were environmentally impactful, but they were also consequential in terms of socio-politics $[1-3,9,10]$. Technological choices were also choices about social relationships, including the scale and distribution of human settlement, the balance of power among various social groups, and the relative ability (or complete lack of ability) for humans to be free to meet their own needs and comforts through technologies they understand and-at least in part-control.

Amory Lovins argued that a hard energy path, which dominates energy technology infrastructure and energy supply provision, demands "central control" and thus "concentrates political and economic power ... persistently distorts political structures and social priorities, increases bureaucratization and alienation ... (and is) inimical to greater distributional equity within and among nations (as it) inequitably divorces costs and benefits" [2] (p. 148). Therefore, following a hard energy path, our existing energy systems have become impenetrable and un-democratic. People who consume energy largely cannot participate in planning nor can most of us, as energy consumers, understand the intricate details of these large systems.

In contrast, soft energy technologies involve an alternative set of socio-political consequences. Appropriate technologies can be adopted to suit local biophysical conditions, economies, and choices of the energy users. As the scale of operation is small and comparably simpler than hard energy technologies, soft energy production systems can be accessible and understood by end users, encouraging them to participate or even own these systems.

Lovins argued that the two approaches of energy development, one hard and one soft, are culturally incompatible because they involve radically different environmental and socio-political consequences [2]. Lovins also argues that the trends of hard path energy systems will continue until and unless there is a change in the social philosophy from one that associates success with fulfilling our material wants through endless energy supply to one that stresses energy as a human right, a social value, and recognizes the relationship between energy production networks and their socio-political consequences [2]. Thus, the renewable energy transition involves real choices, choices in terms of how the transition is discussed (as motivated by narrowly conceived environmental consequences, or as involving real socio-political consequences) and in terms of energy paths and the associated embedded politics. 


\section{Energy Technology Transitions and Climate Change: The Current Framework}

Contemporary discussions of energy technology transitions, however, have largely lost the articulated cogency of the social critique offered by the concepts of soft energy paths and appropriate technologies. Focused on the environmental impacts of fossil fuel energy generation, particularly the impacts of emissions on precipitating climate change, scholars and policy makers alike frame renewable energy technologies as an environmentally beneficial alternative to fossil fuel based electricity generation $[11,12]$. Questions about the optimal scale for developing these technologies have largely been silenced. Renewable energy systems are often assumed to be most rational or efficient at the same scales as fossil fuel based generation, with corporate ownership of mega-generation facilities being a common model for both. For environmental social scientists interested in understanding, promoting, and interrogating the resistance to a renewable energy transition, there is often very little discussion of the socio-political consequences of technological development $[4,11]$. Arguably, this narrow gaze limits opportunities for meaningful consideration of how technological systems work to support, or prevent, the kinds of politics and practices that are most beneficial to both the natural world and human communities. Focusing on the environmental consequences of energy technology ignores the socio-political consequences of these technologies based not only on energy source but also on size and scale as well as modes of ownership and control. Further, focusing on the environmental consequences alone may work to exacerbate division and lack of support for renewable energy technology transitions; people who do not share environmental values or concern may nonetheless have common commitments to individual and community autonomy, resiliency, knowledge, and local control over the technologies that support human life.

Current discussions of energy technology transitions in both scholarly and policy literature frame energy technology primarily in terms of environmental consequences [13-15]; renewable energy technologies are even often referred to as green technologies [11,12]. Even when other factors like energy security or economic development are included, issues of political distribution of material resources and social power are rarely mentioned, and the environmental benefits of renewable energy technologies are espoused as the primary reason to promote a renewable energy transition. Research and policy rhetoric abounds on the importance of transitioning away from a fossil fuel dominated energy matrix for the sake of climate change mitigation [13-15]. Recent research even conceptualizes the negative climate impacts of fossil fuel production relative to renewable energy production in terms of liabilities from avoidable emissions [16]. From the Intergovernmental Panel on Climate Change (IPCC) to President Barak Obama's Clean Power Plan, there is awareness-albeit accompanied by relatively slow action-that an energy transition in which renewable energy technologies are increasingly adopted is an important component of global environmental responsibility.

Arguably, the current conversation frames renewable energy technologies and the possibilities of a renewable energy transition almost exclusively in terms of environmental impacts. Yet particularly considering the U.S. context, political polarization often shapes the conversation about the potential for a renewable energy transition. Because this transition is framed as above all an environmental decision, the divisiveness of environmental issues shapes the politics of renewable energy possibilities. Some scholars have even looked at the relationship between greenhouse gas emissions and political factors, including support for environmentalism defined as a matter of politics [17].

Recognizing the relationship between energy technologies and environmental impacts certainly is not wrong or in any way incorrect; fossil fuel dominant energy technologies do cause unparalleled environmental damage, including the damage from emissions that precipitate and exacerbate climate change. Other, less dominant themes regarding the value of renewable energy technology transitions espoused by politicians like U.S. President Barack Obama, themes including increased national security or the retraining of a robust workforce, are arguably also not wrong. The argument here is that these framings of renewable energy technology are partial at best. They ignore many of the insights offered by Lovins and other authors of the appropriate technology movement regarding the socio-political implications of technology and the socially beneficial socio-politics that accompany 
soft path technologies. By ignoring the real political consequences of technological choices, important elements of the conversation are ignored, such as the ideal scale and scope for renewable energy technology development, the models of technology ownership that ought to emerge from the energy technology transition, how changes to understandings and mechanisms of ownership and control may either result from or precipitate changing technologies and new structures of energy technology development, and how technologies, economies, and issues of social power and equity are related.

Certainly, there are many scholars who recognize the social impacts of energy technologies. Working in the field of environmental justice, there are myriad authors, practitioners, and community members who are deeply aware of how fossil fuel based energy generation impacts both the environment and the health and wellbeing of individuals $[18,19]$. These social impacts, the result of differential power relations such that the largest environmental, health, and social burdens that result from energy technology are placed on those with the least power to resist, are very real experiences for far too many. The realities of environmental injustice are forefront for many environmental social scientists, practitioners, advocates, and affected groups.

However, even among environmental justice scholars, it is rare for a critique of technology to include a consideration of the multiple possibilities that exist for meeting the energy needs of human societies and the ways in which these possibilities represent very different realities in terms of not only environmental impacts but also in terms of socio-politics and individual lives (see [20]). While environmental justice scholars are deeply aware of the differential social consequences of technologies and its intimate tie to the current balance of power, they often do not clearly articulate that this balance of power is itself tied to the current energy technology regime. This work, then, largely takes technology for granted. The narrative of an environmental injustice project may acknowledge the pollution coming from the fossil fuel based power plant, and may recognize that the pollution is having a more significant impact on poorer and less powerful people and social groups and may work for restorative or restitutive justice for the people impacted-but this narrative may ignore entirely the possibility of eliminating the power plant altogether, may ignore that technologies are indeed choices and are not only caused by arrangements of political power but are also associated with particular socio-political consequences, and that different, soft path energy technologies may better serve communities and may themselves work to restore imbalances in the relations of power within society.

This argument about the link between technologies and socio-politics may be an uncomfortable move for some. The appropriate technology movement has been accused of technological determinism [19], of oversimplified conceptualization of the ways technology shapes socio-political relationships. The goal here is not to move toward determinism, nor is it to defend the position of a historical movement with regard to determinism (see [21,22]). Rather, the aim is to bring attention to the ways that technological choices are indeed real choices. Human groups make decisions about the scale at which to develop technology; choices about energy sources and technological scales of development do shape social relationships in terms of both proximity and familiarity with a technology and ability to understand, control, maintain, and provide resilient sustenance at the individual and community scale. In the case of dominant energy technologies, this currently means that most energy is generated in some far off place that consumers of the end use product do not often see and certainly do not control. Technological choices are also choices about technological construction, maintenance, and regulation. Different technologies have different requirements in terms of how, where, and at what scale they can be constructed and how, when, and by whom they are maintained. They also differ in the kinds, scale, and scope of regulation that may apply to them. The systems of construction, maintenance, and regulation ultimately do shape socio-politics, by differentially allocating the ability to build, maintain, or regulate the technological systems upon which real human lives depend. In other words, the argument is that these technological choices are really about power and that the more we (as scholars, or advocates, or users of energy systems) ignore that, the more we obfuscate the real issues of power involved in climate denialism and environmental policy deadlock. By framing energy technology choices as 
exclusively about environmental responsibility and climate change mitigation, both scholarship and policy debates are guilty of ignoring that both environmental issues and technological choices are in the first and last instance implicated in social relations of power. By focusing on the relationship between energy technologies and environmental impacts, conversations about the alternative energy possibilities that best serve both environmental responsibility and human communities are quieted. Further, framing energy technologies as exclusively an environmental issue denies the importance of human practice in the ultimate use of the technologies employed by human societies to meet human needs and comforts.

\section{Energy Transitions, Energy Paths, and Energy Practices}

A second body of scholarship that can arguably contribute to a more nuanced, well rounded, and ultimately realistic understanding of the relationships among technology, power, and social change is found in emerging theories of social practice [23-26]. The term social practice is meant to capture the constellation of habitual bodily action that humans engage in every day, often without conscious awareness, but that organize life through patterns of social engagement. These social practices involve interaction with the material world so that the unit of analysis for studying social behaviors becomes not the individual but the human-technology interface. These social practices, further, are the unthinking enactment of social norms and the unreflexive rituals reinforcing existing technological systems and their corresponding relations of power. As concrete examples, flipping a light switch without thought to the source of electrical power involves different forms of social practice than moving the tilt of a mounted solar panel to maximize production during a specific season or time of day. Driving a private automobile involves forms of social practice that are different from organizing a ride share or carpool. These forms of practice arguably correspond to and reinforce particular politics.

Theories of social practices work to explain both the persistence and the potential for change in the material systems of organization that shape human societies, arguing that technologies are often mobilized through systems of provision that configure the kinds of bodily habits involved in daily life $[27,28]$. These theories are attentive to practice, shared habits of bodily engagement, as a unit of analysis that connects structural constraints and individual action, recognizing energy technologies as perpetuating politics of practice. In addition to shaping the distribution of power and resources in society, energy technologies shape what individual people actually do on a day-to-day basis, the physical bodily individual actions that involve shared, social bodily habits and patterns. The organization of energy technology shapes the organization of social life, both in terms of politics and in terms of practice. Further, these practices reinforce and stabilize particular politics.

Energy technologies correspond to socio-political consequences; they also shape social practice. Conceptualizing energy usage as a bundle of habitual, unthinking patterns of behavior is important for recognizing that renewable energy transitions based on hard path design do not demand changes in practice. Yet if we take practice theory seriously, it may only be through changed practice that human societies realize their full capabilities for energy awareness, energy efficiency, and ultimately energy justice $[29,30]$. Thinking in terms of how energy technologies shape social practice may also provide a frame that consolidates agreement rather than disagreement about the importance of the renewable energy technology transition based on the path of a soft energy future.

When renewable energy technology transitions are framed exclusively in terms of environmental motivations and benefits, the current scale of these technologies is left unquestioned, such that renewable energy technology systems are developed corresponding to existing energy infrastructures, with large-scale generation and transmission systems rather than flexible and distributed systems. As such, they provide the same kind of end use energy experience; the lights come on at the flip of a switch, and there is no feedback between energy availability and energy use. In contrast, distributed energy systems can be designed to provide such feedback. In response, energy practices change. For example, residential solar electric technology adopters do pay attention to available systems 
measuring energy production and consumption and do change energy practices accordingly [31]. Other studies of alternative technology adoption present similar findings; when the source, size, and scale of technologies are reconfigured, new forms of social practice emerge, which are both environmentally and socially beneficial [32]. Taking the logic of theories of practice seriously means contending with the socially contextual nature of rationality; it is only within existing socio-technical matrices that human thought and practice merge in what is considered rational or irrational action [33]. Renewable energy technologies developed at the same scale and scope as currently dominating, fossil fuel based technologies may emit less carbon, but they will not reconfigure energy use practices. As such, they may limit the potential for retooling the social patterns of energy use through situated social practices that ultimately benefit human communities through reconfigured relations of power.

\section{Politics, Practice, and Policy Implications}

The argument presented here is particularly based on the United States, where renewable energy technologies are often presented as environmentally motivated "green" alternatives [12-15], yet environmental issues are politically divisive and contentious [4,5,34]. Recent research suggests this polarization, while less pronounced, occurs in Europe as well [35]. Given this context, framing renewable energy technologies as an environmentally beneficial or climate responsible technology option in the energy transition may in itself limit public support.

Renewable energy technologies based on appropriate scales and scopes, based on principles of a soft energy path, can promote political transitions that increase community resilience and local control. These political consequences of a renewable energy transition may offer a policy lens for garnering public support for technology development and implementation. Attentiveness to the political consequences of technological development also offers potential new insight for understanding resistance to renewable energy technological development projects, suggesting that research should move beyond a "not in my backyard" (often termed NIMBY) or environmental justice frame to explore public perceptions of the politics of technologies [36], the kinds of political futures desired by local communities, and the technologies that can best help to foster those futures. In other words, instead of interrogating the kinds of technological systems that receive public support, perhaps social change begins by interrogating the kinds of political arrangements, arrangements regarding access to the knowledge and resources that support human life, are publicly desired and then working to develop technological systems that meet energy needs while corresponding to desired politics.

There is evidence of support for this kind of shift. Decentralized, non-governmental community-owned energy systems are increasingly becoming common in different European countries [37-40]. These energy units are developed for the people of the community with the participation of the people of the community following democratic principles. Community members associate a sense of identity, autonomy, self-reliance, and sustainability with community driven projects [41]. In different European countries, government policies and initiatives that support community-driven energy projects have risen in recent years [42,43]. Some community energy projects are explicitly developed in response to frustration with state and market path dependency on large fossil fuel-based energy production [40-42]. Yet despite the increased prevalence of community-scale energy development projects, the importance of framing the renewable energy transition in terms of an explicit focus on soft path technologies and the kinds of socio-political arrangements and distributions of power that they support is, arguably, largely absent from discourse on the renewable energy transition.

Recognizing the consequences of technological development for politics and practice also offers a means of evaluating existing policies meant to promote renewable and sustainable energy systems. In the U.S. context, there is no federal renewable energy policy mandate. States are highly variable in the kinds of incentives they offer for residential renewable energy technology adoption and the extent to which they allow or compensate for net metered electricity that is fed back into the utility grid [44]. Yet adopters do pay attention to the particulars of these policies, changing their practices 
and even timing their decisions to adopt based on them [31]. Net metering policies can be evaluated, and arguably changed, based on the extent to which they promote the politics of a soft path energy system, maximizing local control and energy accessibility.

Further, at least in the U.S. context, policies at the local level are instrumental in shaping the extent to which individuals and communities can pursue appropriate technologies and the corresponding politics and practices. Intentional communities and other alternative forms of residential dwelling can be structured to maximize both the environmental and social benefits of soft path energy technologies, changing the distribution of access to energy infrastructure, knowledge, and security while also reconfiguring social practice $[30,45]$. Organizational and political structures at the local level may offer a first avenue for creating the kinds of policy change necessary to support an appropriately scaled renewable energy future.

\section{Conclusions}

Framing renewable energy technologies exclusively in terms of environmental benefit dismisses important questions about how energy infrastructures can be designed to correspond to the forms of socio-politics desired by human beings, forms of social organization that involve independence in terms of meeting energy needs, resilience in terms of adapting to change, democratic participation, equitable distribution of knowledge and efficacy, and just distribution of ownership and control. Decisions about energy technologies are inherently political, in that the forms of energy infrastructure, the hard or soft paths of development, have real socio-political consequences. Ignoring these consequences leaves important elements out of the conversation about the renewable energy transition; arguably, it also creates a more divisive context for pursuing this transition, as environmental issues are arguably more polarizing than issues of local autonomy, community resilience, and social equity.

Much of the research, policy framing, and advocacy work related to renewable energy technology adoption focuses on the environmental benefits of these technologies. This focus largely ignores the real socio-political consequences of technological choices. The classic work of Amory Lovins aptly argued that energy technology choices are very much social and political choices, as technologies have embedded socio-political consequences. Framing technology in terms of hard path versus soft path technologies, Lovins was interested in soft path or what others have called appropriate technologies. Technologies that are small-scale, distributed, designed based on local social and ecological conditions, and locally owned and controlled can contribute to community wellbeing, resiliency, and participatory democratic politics. Renewable energy technologies can be developed in ways that promote socio-political conditions of democracy, participatory engagement, social equity, and community resilience. However, focusing primarily on the environmental benefits of renewable energy technologies ignores these potential socio-political consequences. Thus, these technologies are largely being promoted at scales and scopes that correspond to current technological organization, leaving the socio-political consequences of the hard path technologies that currently dominate the energy technology landscape unchanged. Furthermore, renewable energy technology development at scales corresponding to the currently dominating organization of energy technology, including centralized generation and utility-scale distribution, does not engage with the possibilities to change energy practices. Engaging with both the political consequences of energy technologies and the ways that energy technologies shape practices of energy usage, recognizing that there are real choices involved in the scale, scope, and form of renewable energy technology deployment and that different technologies involve different politics and practices, is arguably necessary to truly engage with the possibilities of a renewable energy technology transition. Given the political contentiousness of climate change and other environmental issues, a focus on the possibilities for changes in politics and practices through renewable energy technology may also provide a means to promote and facilitate public support for a renewable energy future that supports energy justice, community resilience, and participatory democratic politics. 
Author Contributions: While first author Chelsea Schelly was initially invited to contribute this concept paper and had the initial idea for the paper, she and co-author Aparajita Banerjee worked together with equal contributions to develop the argument and to draft and edit the manuscript.

Conflicts of Interest: The authors declare no conflict of interest.

\section{References}

1. Lovins, A.B. Energy strategy: The road not taken. Foreign Aff. 1976, 55, 186-217. [CrossRef]

2. Lovins, A.B. Soft Energy Paths: Toward a Durable Peace, 1st ed.; Friends of the Earth International: San Francisco, CA, USA, 1977.

3. Lovins, A.B. Soft Energy Technologies. Annu. Rev. Energy 1978, 3, 477-517. [CrossRef]

4. Gromet, D.M.; Kunreuther, H.; Larrick, R.P. Political Ideology Affects Energy-Efficiency Attitudes and Choices. Proc. Natl. Acad. Sci. USA 2013, 110, 9314-9319. [CrossRef] [PubMed]

5. Goldstein, N.J.; Cialdini, R.B.; Griskevicius, V. A Room with a Viewpoint: Using Social Norms to Motivate Environmental Conservation in Hotels. J. Consum. Res. 2008, 35, 472-482. [CrossRef]

6. Winner, L. The Whale and the Reactor; University of California Press: Berkeley, CA, USA, 1986.

7. Pfaffenberger, B. Technological Dramas. Sci. Technol. Hum. Values 1992, 17, 282-312. [CrossRef]

8. Kirk, A. Counterculture Green: The Whole Earth Catalog and American Environmentalism; University of Kansas Press: Lawrence, KS, USA, 2001.

9. Illich, I. Tools for Conviviality; Harper \& Row: New York, NY, USA, 1973.

10. Illich, I. Toward a History of Needs; Pantheon Books: New York, NY, USA, 1978.

11. Wiser, R.H. Green power marketing: Increasing customer demand for energy. Util. Policy 1998, 7, 107-119. [CrossRef]

12. Lorenzen, J.A. Going Green: The Process of Lifestyle Change. Sociol. Forum 2012, 27, 94-116. [CrossRef]

13. Union of Concerned Scientists. Benefits of Renewable Energy Use. Available online: http://www.ucsusa. org/clean_energy/our-energy-choices/renewable-energy/public-benefits-of-renewable.html\#.V-LVY6IrLx4 (accessed on 19 September 2016).

14. Panwar, N.L.; Kaushik, S.C.; Kothari, S. Role of renewable energy sources in environmental protection: A review. Renew. Sustain. Energy Rev. 2011, 15, 1513-1524. [CrossRef]

15. Environmental Protection Agency. Renewable Energy in the Green Power Plan. Available online: https: //www.epa.gov/sites/production/files/2015-11/documents/fs-cpp-renewable-energy.pdf (accessed on 19 September 2016).

16. Heidari, N.; Pearce, J.M. A review of greenhouse gas emission liabilities as the value of renewable energy for mitigating lawsuits for climate change related damages. Renew. Sustain. Energy Rev. 2016, 55, 899-908. [CrossRef]

17. Dietz, T.; Frank, K.A.; Whitley, C.T.; Kelly, J.; Kelly, R. Political influences on greenhouse gas emissions from U.S. states. Proc. Natl. Acad. Sci. USA 2015, 112, 8254-8259. [CrossRef] [PubMed]

18. Downey, L. Democracy, Inequality, and the Environment; New York University Press: New York, NY, USA, 2015.

19. Evans, G.; Phelan, L. Transition to a post-carbon society: Linking environmental justice and just transition discourses. Energy Pol. 2016. [CrossRef]

20. Shiva, V. Soil Not Oil: Environmental Justice in an Age of Climate Crisis; North Atlantic Books: Berkeley, CA, USA, 2015.

21. Eckaus, R.S. Appropriate technology: The movement has only a few clothes on. Issues Sci. Technol. 1987, 3, $62-71$.

22. Schnaiberg, A. Redistributive Goals versus Distributive Politics: Social Equity Limits in Environmental and Appropriate Technology Movements. Sociol. Inq. 1983, 53, 200-215. [CrossRef]

23. Hollick, M. The Appropriate Technology Movement and its Literature: A Retrospective. Technol. Soc. 1982, 4, 213-229. [CrossRef]

24. Reckwitz, A. Toward a Theory of Social Practice: A Development in Culturalist Thinking. Eur. J. Soc. Theory 2002, 5, 243-263. [CrossRef]

25. Jaefer-Erben, M.; Offenberger, U. A Practice Theory Approach to Sustainable Consumption. GAIA 2014, 23, 166-174. [CrossRef] 
26. Kennedy, E.H.; Cohen, M.J.; Krogman, N.T. Putting Sustainability into Practice: Applications and Advances in Research on Sustainable Consumption; Edward Elgar: Cheltenham, UK, 2015.

27. Schelly, C. How policy frameworks shape environmental practice: Three cases of alternative dwelling. In Putting Sustainability into Practice: Advances and Applications of Social Practice Theories; Kennedy, E.H., Cohen, M.J., Cheltanham, N.K., Eds.; Edward Elgar: Cheltenham, UK, 2016; pp. 185-203.

28. Spaargaren, G. Sustainable consumption: A theoretical and environmental policy perspective. Soc. Nat. Resour. 2003, 16, 687-701. [CrossRef]

29. Sovacool, B.K.; Sidortsov, R.V.; Jones, B.R. Energy Security, Equality and Justice; Routledge: New York, NY, USA, 2013.

30. Sovacool, B.K.; Dworkin, M.H. Global Energy Justice; Cambridge University Press: Cambridge, MA, USA, 2014.

31. Schelly, C. Residential Solar Electricity Adoption: What Motivates, and What Matters? A Case Study of Early Adopters. Energy Res. Soc. Sci. 2014, 2, 183-191. [CrossRef]

32. Boyer, R. Achieving One-Planet Living through Transitions in Social Practice: A Case Study of Dancing Rabbit Ecovillage. Sustain. Sci. Pract. Policy 2016, 12, 1-13.

33. Bourdieu, P. Outline of a Theory of Practice; Cambridge University Press: Cambridge, MA, USA, 1977.

34. Dunlap, R.E.; McCright, A.M.; Yarosh, J.H. The political divide on climate change: Partisan polarization widens in the U.S. Environ. Sci. Policy Sustain. Dev. 2016, 58, 4-23. [CrossRef]

35. McCright, A.M.; Dunlap, R.E.; Marquart-Pyatt, S.T. Political ideology and views about climate change in the European Union. Environ. Pollut. 2016, 25, 338-358. [CrossRef]

36. Schelly, C. What's political about solar electric technology? The user's perspective. Engag. Sci. Technol. Soc. 2015, 1, 25-46. [CrossRef]

37. Hargreaves, T.; Hielscher, S.; Seyfang, G.; Smith, A. Grassroots innovations in community energy: The role of intermediaries in niche development. Glob. Environ. Chang. 2013, 23, 868-880. [CrossRef]

38. Oteman, M.; Wiering, M.; Helderman, J. The institutional space of community initiatives for renewable energy: A comparative case study of the Netherlands, Germany and Denmark. Energy Sustain. Soc. 2014, 4, 1-17. [CrossRef]

39. Walker, G. What are the barriers and incentives for community-owned means of energy production and use? Energy Policy 2008, 36, 4401-4405. [CrossRef]

40. Walker, G.; Devine-Wright, P. Community renewable energy: What should it mean? Energy Policy 2008, 36, 497-500. [CrossRef]

41. Bomberg, E.; McEwen, N. Mobilizing community energy. Energy Policy 2012, 51, 435-444. [CrossRef]

42. Peters, M.; Fudge, S.; Sinclair, P. Mobilising community action towards a low-carbon future: Opportunities and challenges for local government in the UK. Energy Policy 2010, 38, 7596-7603. [CrossRef]

43. Seyfang, G.; Park, J.J.; Smith, A. A thousand flowers blooming? An examination of community energy in the UK. Energy Policy 2013, 61, 977-989. [CrossRef]

44. Schelly, C.; Price, J. Utilizing GIS to examine the relationship between state Renewable Portfolio Standards and the adoption of renewable energy technologies. ISPRS Intl. J. Geo-Inf. 2014, 3, 1-17. [CrossRef]

45. Schelly, C. Are residential dwellers marking and claiming? Applying the concepts to humans who dwell differently. Environ. Plan. D Soc. Space 2014, 32, 672-688. [CrossRef]

(C) 2016 by the authors; licensee MDPI, Basel, Switzerland. This article is an open access article distributed under the terms and conditions of the Creative Commons Attribution (CC-BY) license (http://creativecommons.org/licenses/by/4.0/). 